\title{
Reproductive biology and morphometric characters of the Squid Loligo forbesi (Cephalopoda: Loligindae) in the Suez bay, Red Sea, Egypt
}

\author{
Howaida R. Gabr ${ }^{1}$ and Rafik Riad ${ }^{2}$ \\ I-Department of Marine Sciences. Faculty of Sciences, Suez Canal University, \\ Isnailia. Egypt. \\ 2- National Institute of Oceanography and Fisheries, Alexandria, Egypt \\ hgabr_suezcanal@yahoo.com \\ Rafik_Riad67@yahoo.com
}

\begin{abstract}
$\mathrm{R}$ eproductive biology and morphometric variation of male and female Loligo forbesi were investigated from samples obtained from commercial catches in Suez bay. The samples were collected seasonally between 2005 and 2006 . The results of sex ratio indicated that females outnumber males during peak periods of reproduction. Based upon morphological features of the gonads, three maturity stages were described in both sexes. Depending on the proportion of each maturity stage, as well as various maturity indices (gonad somatic index, GSI and nidamental gland index, NGI) the spawning season was found to take place during spring and early summer. Sexual dimorphism is evident in $L$. forbesi, where the males grow more rapidly than do females and achieve larger sizes. The mean size at maturity was 106 and $104 \mathrm{~mm}$ dorsal mantle length (DML) for males and females respectively. Potential fecundity estimates were obtained by counting eggs and ova in the oviduct and ovary of mature females and were in the range of 4985 to 12427 (mean $=9633 \pm 1555$ ). There was a weak relationship between ova number and mantle length but a reasonable positive correlation was reported. The ovaries of mature females contained eggs of various sizes, indicating that spawning probably occurs intermittently. Comparisons of external morphometric characters between males and females of $L$. forbesi indicated a high overlapping between the sexes. Sexual dimorphism was limited to few measurements.
\end{abstract}

Key words: Loliga forbesi, reproductive biology, morphometric characters, Suez bay.

\section{INTRODUCTION}

Coleoid cephalopods have traditionally been considered to exhibit semelparous life cycles (Calow, 1987), with a short life-span and rapid early growth, being followed by maturation, spawning and death. Semelparous females lay eggs in one single spawning bout or in several consecutive bouts, with no pause between each, after which they die. The animals with this reproductive pattern, where gonad regeneration is absent, are semelparous. Iteroparous species are those in which gonadal regeneration follows spawning, 
making a new reproductive cycle. However, in cephalopods different degrees of semelparity may occur. This diversity may be related to growth patterns (Mangold-Wirz et al., 1993). Some cephalopods are simultaneous terminal spawners; where ovulation is synchronous and egg-laying occurs shortly at the end of the animal's life, and no continued oocyte maturation during the spawning period. This type of spawning has also been called terminal spawning and single spawning (Calow, 1987). Other species have intermittent terminal spawning where partial ovulation occurs during the spawning period. Partial ovulation implies the presence of oocytes at various stages of development in the ovaries. This enables the continued production of ova once spawning has commenced. In the intermittent terminal spawning type, egg-laying occurs in separate batches during the spawning period, which is usually relatively long; although it does not represent the greatest fraction of the animal's life before death (Forsythe and Van Heukelem, 1987; Jackson and Choat, 1992). Intermittent terminal spawning has been referred as "multiple spawning" when somatic growth occurs between separate egg batches (Harman et al., 1989; Lewis and Choat, 1993).

'The squid, Loligo forbesi is a commercially important squid which lives in subtropical and temperate waters of the Eastern Atlantic Ocean and Mediterranean Sea. It is an abundant near-bottom species occurring in Suez bay and is one of the important fishery resources in the bay. It is captured mainly as a by-catch of artisanal trawling techniques and is caught directly by a manual jigging technique. However, in spite of the increased importance of $L$. forbesi fisheries, most of its biological aspects which are necessary for development of a management strategy (reproduction, distribution) are incompletely documented. There are, however, relatively abundant data on this subject in other areas (LumKong, 1992; Boyle and Ngoile, 1993; Moreno et al., 1994; Pierce et al., 1994).

The present study aimed to investigates the sex ratio, size at maturity, variation in maturity stages, variation in maturation indices and potential fecundity of $L$. forbesi at Suez bay. Morphometric characters were also investigated to determine which characters differ significantly between the sexes.

\section{MATERIALS AND METHODS}

Seasonal samples of the squid Loligo forbesi were collected from Suez bay on the Red Sea between 2005 and 2006. The samples were caught by local fishermen using trawling nets. All the animals were frozen and stored till investigation. After thawing at room temperatuice, total body wet weight (BW) to nearest $0.1 \mathrm{~g}$ and dorsal mantle length (ML) to nearest $1 \mathrm{~mm}$ were measured and recorded. Specimens were dissected to determine sex and maturity stage. A simplified system of maturity staging based on a modified Lipiński (1979) scale was used as: I- immature, II- maturing, III- mature. This was necessary because the samples were taken seasonally. Gonad weight (testis in males and ovary and 
nidamental gland in females) to the nearest 0.1 gram were recorded. Female' gonads were preserved in $10 \%$ formalin for detailed study.

Indices of reproductive status for males and females adapted from Pierce et al. (1994) were calculated as follows:

$\mathrm{GSI}=100 \times G W /(B W-(S W+G W))$

Nidamental gland index: $100 \times \mathrm{NGW} /(B W-(S W+N G W))$

where GW is gonad weight, NGW is nidamental gland weight, $\mathrm{BW}$ is body weight and $\mathrm{SW}$ is stomach content weight.

Fecundity was estimated in 30 females that were in stage III (mature) and the samples were skewed towards the females that had spermatophores attached in the buccal mass, or had the seminal receptacle filled with sperm, on the assumption that these individuals had mated recently. $1.0 \mathrm{~g}$ sample of oocytes was taken from the ovary and a $2.0 \mathrm{~g}$ sample from the oviduct. These were fixed in $5 \%$ formaldehyde to harden the eggs and subsequently stored in $80 \%$ alcohol. The samples were counted in a sectioned Petri dish under a dissecting microscope.

The logarithmically transformed regression equation was used to show the relationships between dorsal mantle tength (ML) and total body weight (BW), for males and females $L$. forbesi, based on general relationship $\mathrm{W}=\mathrm{aL}^{\mathrm{b}}$, where $W$ is the total weight, $L$ the mantle length, and $a$ and $b$ are constants.

The following defailed morphmetric measurements were taken in sequence on each animal to the nearest $\mathrm{mm}$, using vernier calipers (Fig. 1). Changes in body form were assessed using the potential allometric equation, $Y=$ $\mathrm{a}+\mathrm{bX}$, where $\mathrm{X}$ was the dorsal mantle length (DML) and $\mathrm{Y}$, the measured body dimensions. The constants $a$ and $b$ represent the intercept and the constant of equilibrium of allometry, respectively, and were calculated by linear regression of the variables $X$ and $Y$.

Dorsal mantle length (DML) - length of the mantle from the posterior tip to the anterior tip measured on the dorsal side.

Head length (HL)- the length of the head measured from anterior tip of the nuchal cartilage to the junction of dorsal arms.

Head width (HW) - the width of the head measured across the anterior edge of the eyes.

Fin length (FL)- the distance from the posterior tip of the mantle to the anterior most tip of the fin.

Fin width (FW)- the width of the fins when fully stretched and measured at the greatest width.

Arm Length (A4) - distance from the proximal-most sucker to the tip of the arm4. Arms are numbered starting from the dorsal side.

Tentacle Length (TL) - distance along tentacle from the point of emergence from webbing between arms III and IV to the tip of the tentacle.

Shell length (PL)-distance between the anterior tip to the posterior tip of the pen. 
Shell width (PW) - greatest width of the pen.

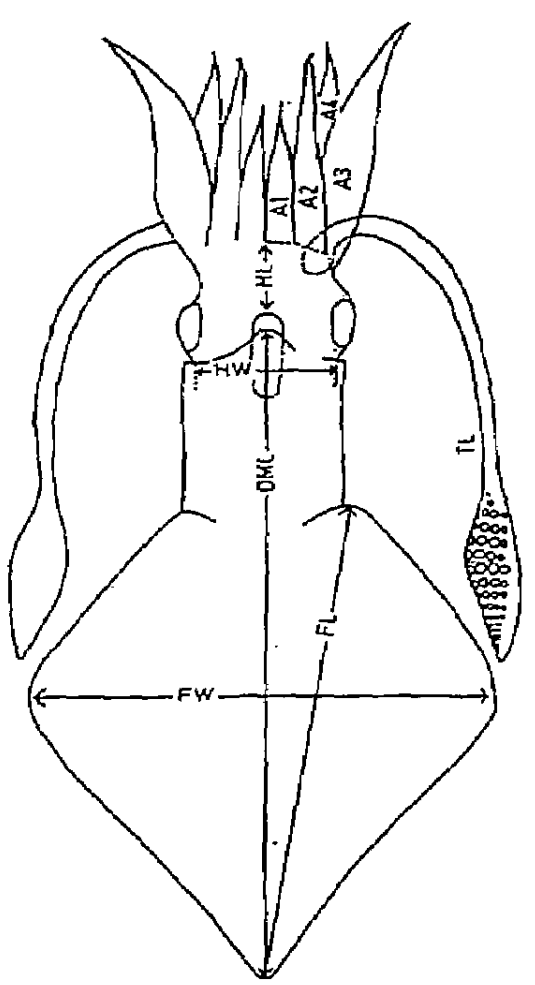

Fig. 1. Diagram illustrating morphometric characteristics measured for Loligo forbesi. $\mathrm{DML}$, dorsal mantle length; $\mathrm{HL}$, head length; HW, head width; FL, fin length; $\mathrm{FW}$, fin winth; $\mathrm{A4}$, length of the fourth arm; $T L$, tentacle length.

\section{Sex ratio}

\section{RESULTS}

Males outnumbered females in all the investigated seasons except summer. In spring, out of a total 187,112 were males $(59.89 \%)$ and 75 were females (40.10). In summer, out of a total 103, 41 were males (39.80) and 62 were females $(60.19)$. In autumn, out of a total 136 collected animals, 87 were males $(63.97 \%)$ and 49 were females (36.02\%). In winter, out of a total 137,83 were males $(60.58 \%)$ and 54 were females $(39.41 \%)$. Chi-square test was used to detect if there is a significant deviation from 1:1 sex ratio. The male to female ratios depart significantly from the assumed ratio $1: 1$ between the seasons (chi $=0.68, \mathrm{p}<0.5$ ).

\section{Size at first maturation}

Size at first maturation is defined as the size at which 50 percent of the individuals are maturing or mature (Bakhayokho, 1983). Figure 2 illustrates the relationship between the proportion of maturing and mature animals (Stages II and III inclusive) and the dorsal mantle lengths (DML) of Loligo forbesi. This 
figure (based on 439 samples taken throughout the sampling period) indicates that the mean size at maturity for males and females was ver close: 106 and 104 $\mathrm{mm} \mathrm{ML}$ for males and females, respectively. The size range of mature animals was ivide, $70-230 \mathrm{~mm}$ ML in males; $70-170 \mathrm{~mm} \mathrm{ML}$ in females.

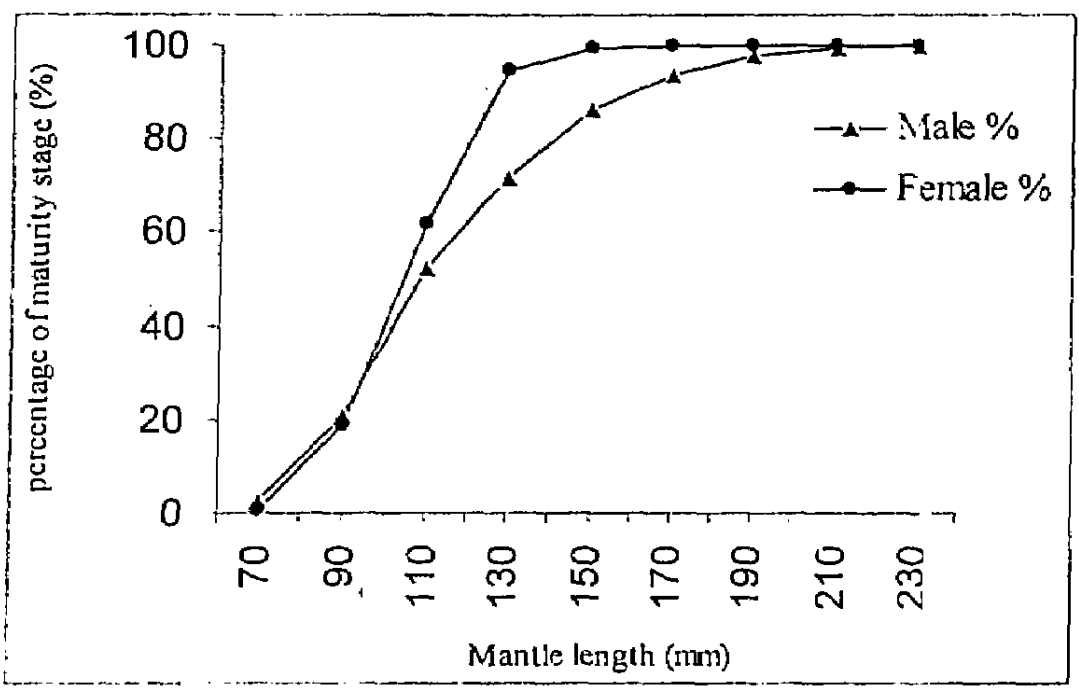

Fig. 2. Percentage of maturing and mature (Stages II \& III) male and temale Loligo forbesi

\section{Seasonal variation in maturity stages}

To determine the spawning season, the occurrence of mature males and females throughout the period of study was examined. Figures 3 and 4 illustrate the seasonal percentage composition of maturity stages of male and female Loligo forbesi, respectively. There is a pronounced peak in the percentage of immature male and females (stage I) during autumn. Maturing males and females (stage II) occurred all year round with variable percentages. The peak incidence of mature animales (stage III) was in spring for males and in summer for females. Meanwhile, some mature squids were present during all seasons.

\section{Seasonal variation in maturity indices}

The pattern of maturation suggested by maturity stages (Figs. 3 and 4 ) is supported by maturity indices data (gonad somatic index, GSI and nidamental gland index, NGI). Seasonal variation in maturity indices of Loligo forbesi was pronounced for both sexes (Figs.5 and 6 for males and females respectively). Female and male maturity indices increased in spring and reached a peak in summer; this coincided with peak percentage of specimens in spawning condition. All maturation indices showed their lowest values in autumn and increased again in winter. 


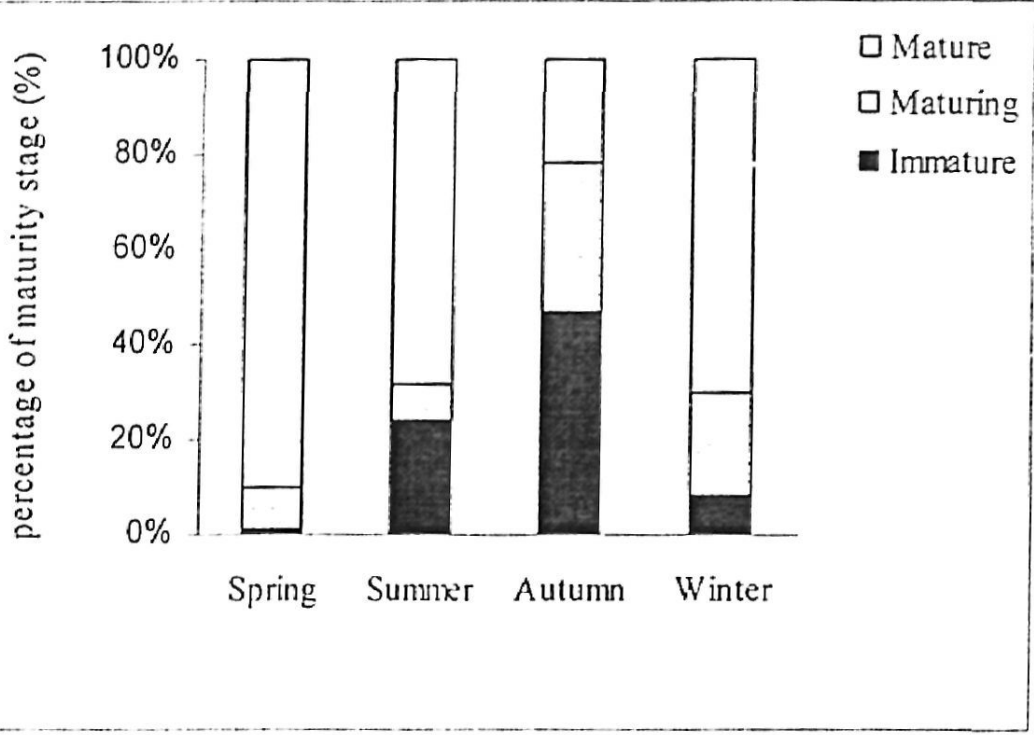

Figure 3. Seasonal variations in male Loligo forbesi at different maturity stages (I - III).

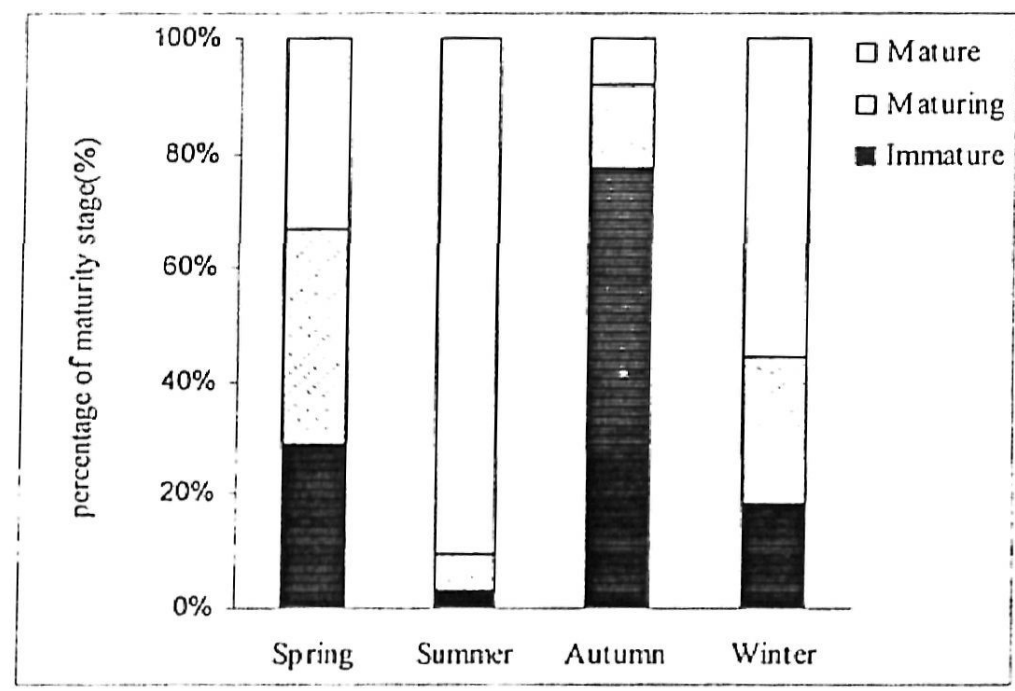

Figure 4. Seasonal variations in Female Loligo forbesi at different maturity stages (I - III).

\section{Fecundity}

The mean total number of ova in mature female (stage III) was $9633 \pm 1555$, ranging from 4985 in a female $118 \mathrm{~mm} \mathrm{ML}, 135.25 \mathrm{~g}$ total weight and an ovary weight of $1.1 \mathrm{~g}$, to 12427 in a female $148 \mathrm{~mm} \mathrm{ML}, 71.5 \mathrm{~g}$ total weight and an ovary weight of $11.93 \mathrm{~g}$. In all specimens examined there was a range of egg development within the ovary; however, oviducal eggs were all of similar size (range $2.6-3.2 \mathrm{~mm}$ ). Clearly there were many immature ova present in the ovary of females that were at or approaching full maturity. 
There was a tendency for the larger females to be more fecund than the smaller ones, although the relationship between the two variables was weak $\left(r^{2}=0.41, N=35\right)$. Such relationship may result from some feniales of similar size which had already laid different.numbers of eggs, since all these individuals appeared to be in spawning condition. The equation relating mantle length and fecundity was: $Y=883.34 \mathrm{X}-1999.3$. The relationship between the number of ova and ovary weight is illustrated by the equation: $Y=458.42 \mathrm{X}+7012$. There was a clear increase in fecundity with increasing ovary weight $\left(r^{2}=0.71, N=35\right)$.

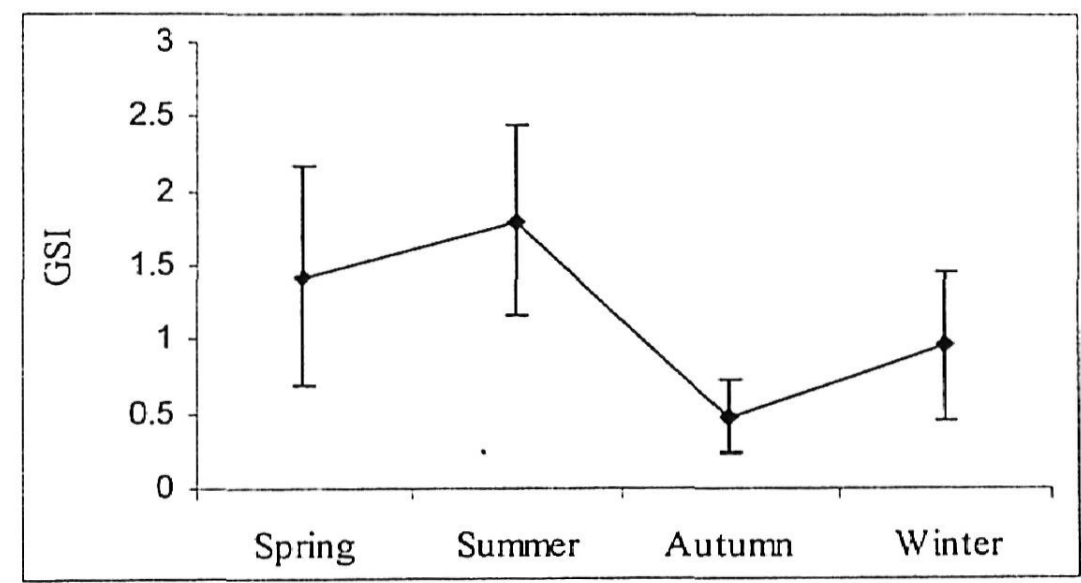

Figure 5. Variation in seasonal means of gonad somatic index (GSI) in male Loligo forbesi.

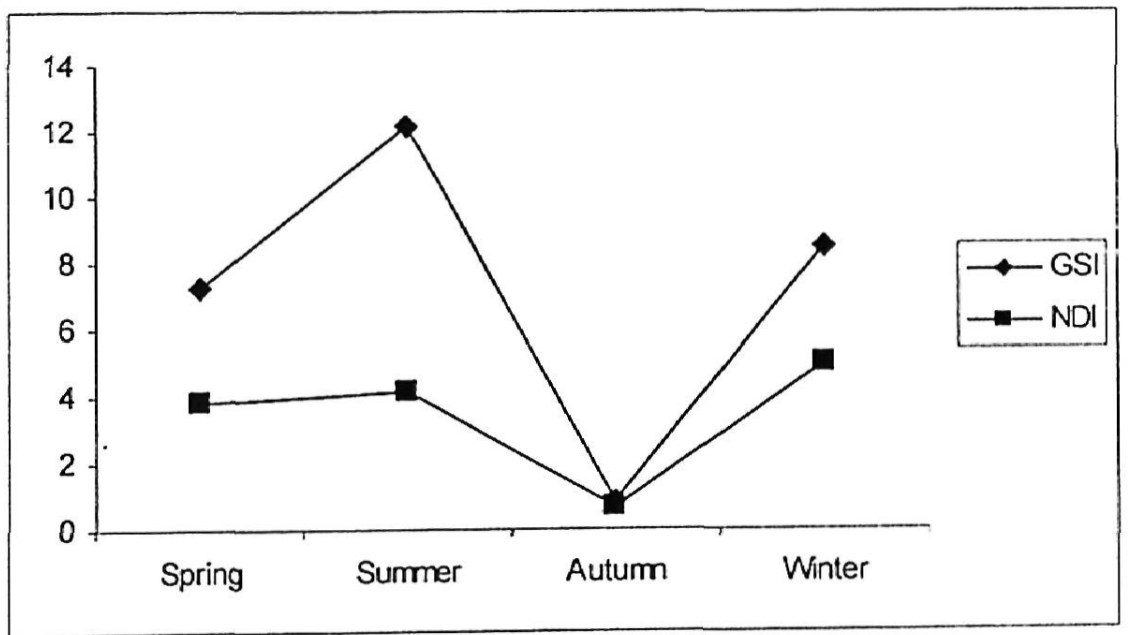

Figure 6. Variation in seasonal means of gonad somatic index (GSI) nidamental gland index (NGI) in female Loligo forbesi.

\section{Length/weight relationship}

The length - weight relationship of Loligo forbesi is described by the following equations: 
$W=0.199 \mathrm{DML}^{2.07} \quad \mathrm{r}^{2}=0.0 .78$ for males

$\mathrm{W}=0.156 \mathrm{DML} \mathrm{D}^{2.24} \quad \mathrm{r}^{2}=0.75$ for females

The relative weight/length constant $b$ was lower in male (2.07) than in female (2.24). This was reflected in the mean weight, where the male was significantly $(p=0.0025)$ lighter than the female of the same length.

Relative growth

The relationships between Mantle length (DML) and each measurement of separate body parts of male and female Loligo forbesi are illustrated by the regression equations in Table 1 . For both sexes, the slopes of the regression lines for most measured body parts showed negative allometric growth (slope less than 1). The only body part that showed positive allometric growth (slope more than 1) was tentacle length (TL). Generally the coefficient of determination $\left(r^{2}\right)$ was high (0.53-0.98) for most measurements (HW, FL, FW, A4. TL, PL, PW), but poor correlations were found between DML and HL $\left(r^{2}<0.50\right)$.

Differences in slopes for the body parts between sexes were tested for significance by analysis of covarianice (ANCOVA:) where the slopes for female and male tentacle length and shell width against mantle length differ significantly $(p<0.05)$. The female tentacle is relatively longer and the pen relatively wider per unit DML $(b=1.63,0.09$ respectively) than those of males $(b=1.07,0.07$ respectively) (Table 1$)$.

Tablel. Regression equations describing the relative growth of dimensions of $\delta$ body parts in male and female Loligo forbesi. $\mathrm{Y}=\mathrm{a}+\mathrm{b}$ DML Independent: Dorsal mantle length (DML)

\begin{tabular}{|l|ccccc|ccccc|}
\hline & \multicolumn{9}{|c|}{ Malc } & \multicolumn{1}{c|}{ Female } \\
\cline { 2 - 10 } Dependent & $a$ & $b$ & $r^{2}$ & $n$ & SD & $a$ & $b$ & $r^{2}$ & $n$ & SD \\
\hline HL & 1.48 & 0.08 & 0.31 & 323 & 0.44 & 0.95 & 0.13 & 0.39 & 240 & 0.41 \\
HW' & 1.08 & 0.08 & 0.57 & 323 & 0.35 & 0.56 & 0.13 & 0.63 & 240 & 0.34 \\
FL & -1.55 & 0.71 & 0.98 & 323 & 2.17 & -0.71 & 0.63 & 0.95 & 240 & 1.22 \\
FW & 0.45 & 0.45 & 0.79 & 323 & 1.49 & -0.63 & 0.57 & 0.72 & 240 & 1.28 \\
A4 & 1.88 & 0.34 & 0.53 & 323 & 1.43 & -0.25 & 0.54 & 0.58 & 240 & 1.35 \\
PL & 4.97 & 1.07 & 0.69 & 323 & 3.81 & -0.65 & 1.63 & 0.61 & 240 & 3.88 \\
PW & 1.40 & 0.94 & 0.95 & 323 & 2.95 & 2.48 & 0.84 & 0.86 & 240 & 1.81 \\
& 0.83 & 0.07 & 0.64 & 323 & 0.26 & 0.73 & 0.09 & 0.39 & 240 & 0.28 \\
\hline
\end{tabular}

Legend: $r$, adjusted correlation coefficient; $n$, number of specimens; $S$, standard deviation.

\section{DISCUSSION}

The sex ratio of Loligo forbesi in the Suez bay showed that the male outnumbered the female in all seasons except in summer when the ratio was skewed towards females. It is possible that the difference between male and 
female abundance could be due to catch bias rather than to population structure, where the small sample sizes need to be taken into consideration. The sex ratio was somehow in agreement with observations by Pierce et al. (1994) in $L$. forbesi in Scottish waters, and Guerra and Rocha (1994) in L. vulgaris in Spanish waters, they found that the sex ratio is related to type of gear, while equal sex ratios were apparent throughout the year except in the peak-spawning period, when females were more numerous than males. Augustyn (1990) and Augustyn et al. (1994) have previously reported a biased ratio in favor of males for chokka on the spawning grounds. This has been reported for other Loligo species i.e. L. forbesi in the Azores (Porteiro and Martins, 1994) and L. vulgaris from the Algarve region in southern Portugal (Coelho et al., 1994) but these estimates were based on jig caught samples and skewed ratios could reflect more attacks on the jigs by males than females rather than greater male abundance (Lipiński, 1994). In the present study, L. forbesi were sampled mainly as a bycatch of artisanal trawling techniques.

Growth and maturation

Loliginid squids have extremely variable growth rates even within a single population. (Collins et al, 1995, 1999; Hatfield, 2000). In the present study, males Loligo forbesi grew to a larger size than females; the maximum size for males was $240 \mathrm{~mm} \mathrm{ML}$ uhile for females was $180 \mathrm{~mm} \mathrm{ML}$. Male loliginids typically show a greater range of size than females (Worms, 1983; Rodhouse et al., 1988; Hatfield et al., 1992). Variability in size-at-maturity appears to be a common phenomenon in cephalopods. Considerable variation has been shown in $L$. opalescens, with females maturing at $81 \mathrm{~mm}$ dorsal mantle length, while other females remain immature until $140 \mathrm{~mm}$ mantle length (Hixon, 1983). MangoldWirz (1983) has also demonstrated that cultured octopuses reared from the same egg mass reach maturity independent of sibling size or age. In agreement with these studies, both sexes of $L$. forbesi showed a wide range in size at maturity. There are various possible explanations of this phenomenon: 1- The animals that mature at small sizes have slower growth rates than those maturing at larger sizes, both being of equivalent ages. 2- Animals that mature at large sizes were 2 years old, having not matured during their first year of life. This implies that there might be two life sparis, one short (i.e. one year) and one long (i.e. more than one year). In this study, the size at first maturation for male and female $L$. forbesi was estimated to be at 106 and $104 \mathrm{~mm} \mathrm{ML}$. Collins et al. (1995) estimated first maturation at 120 and $150 \mathrm{~mm} \mathrm{ML}$ for male and female, respectively of the same species off the east coast of Ireland; their higher value may be a result of selectively sampling larger animals of commercial catches ( $90 \mathrm{~mm}$ upwards).

Seasonal spawning has been described for many loliginid squids i.e. Loligo forbesi and L. vulgaris (Moreno et al., 1994), L. pealei (Lange and Sissenwine, 1980), L. opalescens (Hixon, 1983), L. gahi (Hatfield and Des Clers, 1998; Hatfield, 2000) and in chokka squid (Augustyn et al., 1994). For 
most species, a single peak spawning episode occurs each year although two spawning peaks are suggested for $L$. gahi in Falkland Island waters (Hatfield, 2000) and for L peale $i$ in the NW Atlantic (Brodziak, 1998). Seasonal variation in the maturity stages and maturity indices show that the mature animals of both sexes of $L$. forbesi can be found throughout most of the year and the spawning peak of both sexes occurs during spring and early summer. Pierce et al. (1994) and Collins et al. (1995) observed that spawning of same species in British water extended over long period, peaking during the winter and early spring. This indicates that the spawning season and the reproductive peak for $L$. forbesi are very flexible and probably closely linked to environmental conditions. MangoldWirz (1963) considered the temperature and light as the most important external factors influencing sexual maturation of cephalopods.

Maximum fecundity of Loligo forbesi was estimated at 4985 to 12427 ova for females of 118 to $148 \mathrm{~mm} \mathrm{ML} \mathrm{(mean}=9633 \pm 1555)$ and appears in line with those for $L$. forbesi from Scottish waters (Boyle and Ngoile, 1993) and Spanish waters (Guerra and Rocha, 1994), with larger females typically slightly more fecund. Collins et al. (1995) recorded 2500-10,500 eggs (mean $=5800$ ) for the same species from Ireland water. The presence of a range of eggs development in the ovaries of mature females found here was also reported for L. forbesi in Scottish (Boyle and Ngoile, 1993) and Spanish (Guerra and Rocha, 1994) waters, and may be indicative of intermittent spawning.

Fecundity showed positive correlation with mantle length, but such correlation was generally weak. This can be explained by the fact that loliginids are intermittent terminal spawning (Forsythe and Van Heukelem, 1987) which lay eggs in separate clusters during the spawning period, that is usually relatively long. Thus, some females of similar size may have already deposited different egg clusters, since all these individuals appeared to be in spawning condition.

The calculation of the length-weight relationship showed that the length exponent for weight was less than the expected cubic $(b=3)$ relationship, indicating that weight increases more slowly than a corresponding increase in unit length. Meanwhile, the slopes from the regression equations differ significantly (ANCOVA; $p<0.05$ ), indicating that females are heavier $(b=2.24)$ than males $(b=2.07)$ of the same mantle length. This agrees with similar differences that have been observed in other loliginids (Coelho et al., 1994). The larger weight of female may be related to the fact that the mass of the gonad and accessory reproductive organs constitute a greater proportion of the body mass in females than males at larger sizes, thus for a given length, a female will be heavier than male.

Comparisons of external morphometric characters between males and females of Loligo forbesi were made in an effort to determine their value as a rapid means for fishery biologists to distinguish the sexes in the field. Tests of sexual dimorphism in measured characters regressed against DML for $L$. forbesi 
indicated high overlaping between the sexes. Sexual dimorphism was limited to a few measurements.

In conclusion, the results presented here provide the first detailed information on reproductive patterns, fecundity and morphometric characters of Loligo forbesi in the Suez bay. Such information is critical to the conservation and management strategy of this exploited loliginid species.

\section{REFRENCES}

Augustyn, C. J. (1990). Biological studies on the chokker squid Loligo vulgaris reynaudii (Cephalopoda: Myopsida) on spawning grounds off the southeast coast of South Africa. S. Afr. J. Mar. Sci., 9: 11-26.

Augustyn, C. J.; Lipinski, M. R; Sauer, W. H. H.; Roberts, M. J. and Mitchellinnes, B. A. (1994). Chokka squid on the Agulhas Bank: life history and ecology. S. Afr. J. Sci., 90: 143-153.

Bakhayokho, M. (1983). Biology of the cuttlefish Sepia officinalis hierredda off the Sengalese coast. In : J. P. Caddy (Editor). Advances in Assessment of World Cephalopod Resource. FAO fish. Tech. Pap., 231: 204-263.

Brodziak J. K. T. (1998). Revised biology and management of long-finned squid (Loligo pealei) in the northwest Atlantic. Cal COFI Rep., 39: 61-69.

Boyle. P.R. and Ngoile, N.A.K. (1993). Assessment of matureity state and seasonality of reproduction in Loligs forbesi (Cephalopora:Loliginidae). In: T. Okutani, R. k. O'Dor and T. Kubodera (Editors), Recent Advances in Fisheries Biology, Tokai University Press, Tokyo, pp. 37. 48.

Calow, P. (1987). Fact and Theory- an overview. P. 351-365. In: P. R. Boyle (Editor), Cephalopod Life Cycles, Vol. II, Academic Press, London, England.

Coelho, M. L.; Quintela ,J.; Bettencourt, .; Olavo, G. and Villa, H. (1994). Population structure, maturation patterns, and fecundity of the squid Loligo vulgaris from southern Portugal. Fish. Res., 21: 87-102. 
Collins, M. A.; Boyle, P. R.; Pierce, G. J.; KEY, L. N.; Hughes, S. E. and Murphy, J. (1999). Resolution of multiple cohorts in the Loligo forbesi population from the west of Scotland. ICES J. Mar. Sci. 56: 500-509.

Collins, M. A.; Burnell,G. M. and Rodhouse, P. G.( 1995). Reproductive strategies of male and female Loligo forbesi (Cephalopoda: Loliginidae). J. Mar. Biol. Ass. U.K., 75: 621-634.

Forsythe, J. F. and Van Heukelem, W. F. (1987). Growth. P. 135-156. In P. R. Boyle, (Editors), Cephalopod Life Cycles, Vol. II, Comparative reviews. Academic Press, London. 441 pp.

Guerra, A. and Rocha, F. (1994). The life history of Loligo vulgaris and Loligo forbesi (Cephalopoda: Loliginidae) in Galician waters (NW Spain). Fish. Res., 21: 43-69.

Harman, R. F.; Young, R. E.; Reid, S. B.; Mangold-Wirz, K.; Suzuki, T. and Hixon, R.F. (1989). Evidence fo: multiple spawning in the tropical oceanic squid Sthenoteuthi oualaniensis (Teuthoidae: Ommastrephidae). Mar. Biol., 101: 513-519.

Hatfield, E. M. C. (2000). Do some like it hot? Temperature as a possible determinant of variability in the growth of Patagonian squid Loligo gahi (Cephalopoda: Loliginidae). Fish. Res., 47:-27-40.

Hạtfield, E. M. C. and Des Clers, S. ( 1998). Fisheries management and research for Loligo gahi in the Falklano Islands. CalCOFI Rep., 39: 81-99.

Hatfield, E. M. C.; Rodhouse, P. G. and Barber, D. L. (1992). Production of soma and gonad in maturing female llex argentinus (Mollusca: Cephalopoda). J. Mar. Biol. Ass. U.K., 72: 281-291.

Hixon, R. F. (1983). Loligo opalescens. P. 95-114. In: P. R. Boyle (Editor), Cephalopod Life Cycles, Vol. I, Comparative reviews. Academic Press, London. $441 \mathrm{pp}$.

Jackson, G. D. and Choat, J. H. (1992). Growth in tropical cephalopods: an analysis based on statolith microstructure. Can. J. Fish. Aquat. Sci., 49 (2): $218-228$. 
Lange, A. M. T. and Sissenwine, M. P. (1980). Biological considerations relevant to the management of squid (Loligo pealei and Illex illecebrosus) of the northwest Atlantic. Mar. Fish. Rev., 42: 23-38.

Lewis A. R. and Choat, J. H. (1993). Spawning mode and reproductive output of the tropical cephalopod Idiosepius pygmaeus. Can. J. Fish. Aquat. Sci., 50(1): 20-28.

Lipinski, M. (1979). Universal maturity scale for the commercially important squids. The results of maturity classification of the Illex illecebrosus (Lesueur, 1821) population for years

1973-1977. Res. Doc. 79/11/38. Serial No. 5364, International Commission for Northwest Atlantic Fisheries, 40 pp.

Lipinski, M. (1994). Differences among basic biological parameters in a population of chokka squid Loligo vulgaris reynaudii (Cephalopoda: Loliginidae) sampled by three methods. S. Afr. J. mar. Sci., 14: 281-286.

Lum Kong, A. (1992). A histological study of the accessory reprodictive organs of female Loligo forbesi (Cephalopoda: Loliginidae). J. Zool. Lond., 226: $469-490$.

Mangold-Wirz, K. (1963). Biologie, des cèphalópodes benthiques et nectoniques de la Mer Catalane. Vie Milieu. Supple., 13: 285pp.

Mangold-Wirz, K. (1983). Food, feeding and growth in cephalopods. Mem. Natn. Mus. Vict., 44: 81-83.

Mangold-Wirz, "K.; Young, R. E. and Nixon, M. (1993). Growth versus maturation in cephalopods. P. 697-704. In: T. Okutani, R. K. O'Dor and $T$. Kubodera (Editors), Recent dvances in Cephalopod Fisheries Biology, Tokai University press, Tokyo, Japan.

Moreno, A.; Da Cunha, M. M. and Pereira, J. M. F. (1994). Population biology of veined squid Loligo forbesi and European squid Loligo vulgaris from the Portuguese coast. Fish. Res., 21: 71-86. 
Pierce, G. J.; Boyle, P. R. L; Hastie, C. and Begona Santos, M. (1994). Diets of squid Loligo forbesi and Loligo vulgaris in the northeast Atlantic. Fish. Res., 21: 149-163.

Porteiro, F. M. and Martins, H. R. (1994). Biology of Loligo forbesi Steenstrup, 1856 (Mollusca: Cephalopoda) in the Azores: sample composition and maturation of squid caught by jigging. Fish. Res., 21: 103-114.

Rodhouse, P. G.; Swinfen, R. C. and Murray, A. W. A. (1988). Life cycle, demography and reproductive investment in the myopsid squid Alloteutbis subulata. Mar. Ecol. Prog. Ser., 45: 245-253.

Worms, J., 1983. Loligo vulgaris. In: P. R. boyle (Editors), Cephalopod Life Cycles, Species Accounts, Vol.1. Academic Press, London, pp. 143-158. 